\title{
Extensão no ensino superior: elo entre teoria e prática na aprendizagem significativa
}

A Universidade tem um papel fundamental como integradora entre diferentes realidades e também de aproximar conhecimentos teóricos e práticos, através dos três pilares de ensino, pesquisa e extensão. Dessa forma, teve como principal objetivo aproximar os conhecimentos teóricos de uma área relevante para a Engenharia de Alimentos (química e física) às práticas e experimentações através de oficinas e minicursos para ensino regular. Na realização das oficinas integrantes do projeto de extensão, foi possível despertar o senso de cooperação e interesse nas disciplinas de física e química, através de atividades práticas que resultaram no bem comum, e fortaleceram o senso de solidariedade e o gosto pelo estudo. O vínculo com a comunidade local é fundamental para criar soluções para as problemáticas que envolvem a prática docente.

Palavras-chave: Universidade; Oficinas de extensão; Conhecimento.

\section{Extension in higher education: Link between theory and practice in meaningful learning}

The University has a fundamental role as an integrator between different realities and also to bring together theoretical and practical knowledge, through the three pillars of teaching, research and extension. Thus, its main objective was to bring theoretical knowledge from a relevant area for Food Engineering (chemistry and physics) to practices and experiments through workshops and short courses for regular education. In the realization of the workshops that are part of the extension project, it was possible to awaken the sense of cooperation and interest in the disciplines of physics and chemistry, through practical activities that resulted in the common good, and strengthened the sense of solidarity and the taste for study. The link with the local community is essential to create solutions to problems that involve teaching practice.

Keywords: University; Extension workshops; Knowledge.

Topic: Ensino Superior, Pesquisa e Extensão

Reviewed anonymously in the process of blind peer.
Received: 20/06/2020

Approved: $29 / 07 / 2020$
Wesley Pinto Hoffmann (D) Universidade de Passo Fundo, Brasil http://lattes.cnpq.br/5386628110517076 http://orcid.org/0000-0002-5814-1573 wesleywph@gmail.com

Juliana Maria de Paula (it) Universidade do Estado de Mato Grosso, Brasil

http://lattes.cnpq.br/0775113649202852 http://orcid.org/0000-0002-4960-1558 depaulajm@outlook.com

\section{Evelyn Fernanda Dias}

Universidade do Estado de Mato Grosso,

Brasil

evellynfd17@gmail.com
Roselia Araújo

Universidade do Estado de Mato Grosso, Brasil

roselia.araujo@outlook.com.br

Edwyn de Britto Sodré

Universidade do Estado de Mato Grosso, Brasil

http://lattes.cnpq.br/2613682825728363 edwyn vb@hotmail.com

João de Deus Felipe Scotti

Universidade do Estado de Mato Grosso, Brasil

oaodedeus414@gmail.com

Sumaya Ferreira Guedes
Universidade do Estado de Mato Grosso,
Brasil
http:///attes.cnpq.br/87098666585453750
$\underline{\text { http://orcid.org/0000-0002-1676-6030 }}$
$\underline{\text { su sumaya@yahoo.com.br }}$
Claudinéia Aparecia Queli Geraldi
Universidade do Estado de Mato Grosso,
Brasil
http://lattes.cnpq.br/0165106391032005
http://orcid.org/0000-0001-5255-9752
claudigeraldi@onda.com.br
Sumária Sousa e Silva 10
Universidade do Estado de Mato Grosso,
Brasil
http://lattes.cnpq.br/9221384636856458
http://orcid.org/0000-0001-7901-1316
sumariasousa@gmail.com

Raquel Aparecida Loss (iD) Universidade do Estado de Mato Grosso, Brasil

http://lattes.cnpq.br/3925129970802016 http://orcid org/0000-0002-6022-7552 raquelloss@unemat.br
Referencing this:

HOFFMANN, W. P.; PAULA, J. M.; DIAS, E. F.; SODRÉ, E. B.; SCOTTI, J. D. F.; GUEDES, S. F.; GERALDI, C. A. Q.; SILVA, S. S.; LOSS, R. A.. Extensão no ensino superior: elo entre teoria e prática na aprendizagem significativa. Humanum Sciences, v.2, n.2, p.33-39, 2020. DOI: http://doi.org/10.6008/CBPC2674-6654.2020.002.0003 


\section{INTRODUÇÃO}

As concepções de Educação atuais têm como consenso a formação de valores para a construção da cidadania, como a solidariedade e respeito às diferenças. As demandas de ensino atuais requerem alinhamento entre teoria e prática desde as disciplinas da educação básica regular. A Universidade tem um papel fundamental como integradora entre diferentes realidades e também de aproximar conhecimentos teóricos e práticos, através dos três pilares de ensino, pesquisa e extensão (SAUER, 2018).

Alicerçada também pela formalidade legal, a extensão universitária proporciona integração dos saberes construídos na universidade aos saberes existentes na comunidade. A integração de saberes, nas universidades comunitárias, pode acontecer de forma mais consistente, por ser um modelo de universidade orientado pela missão comunitária, abarca as atividades internas da academia e o desenvolvimento socioeconômico das regiões de sua abrangência. (SAUER, 2018)

Sendo assim, as Instituições de Ensino Superior (IES) são capazes de contribuir para a formação de valores e aproximação entre conteúdo e prática, com práticas situadas através da extensão universitária. Oficinas e cursos de formação complementar são opções viáveis de interferência nas escolas de ensino regular, que percebem intervenções externas como uma oportunidade de agregar novas competências e habilidades requeridas para aliar os diferentes conhecimentos científicos (FREIRE, 1991).

A implementação de minicursos e de oficinas que envolvem química e física aos alunos têm como objetivo fomentar as práticas de ensino necessárias para a formação dos estudantes e futuros profissionais. Nessa constante, durante o desenvolvimento dessas atividades complementares, competências e habilidades necessárias para a construção dos sujeitos sociais podem ser desenvolvidas de maneira efetiva e benéfica para toda a comunidade escolar.

Compreendemos que nos processos de ensino e aprendizagem, o contexto deve ser avaliado e valorizado pelos professores. Conforme Vygotsky (2002), o aprendizado efetivamente ocorre quando se atua através do conceito de zona de desenvolvimento proximal, compreendendo a educação como um progresso constante na capacidade de interação e cooperação do indivíduo com as pessoas em seu contexto, sendo que uma vez vinculados, esses processos tornam-se parte das conquistas no desenvolvimento, que são sociais (VYTGOTSKY, 2002).

Ademais, o conceito de competência estrutura-se na "mobilização de conhecimentos (conceitos e procedimentos), habilidades (práticas, cognitivas e socioemocionais), atitudes e valores para resolver demandas complexas da vida cotidiana, do pleno exercício da cidadania e do mundo do trabalho" (BRASIL, 2017). Posto isso, destacamos que o documento contém dez competências gerais, onde se verificam ações que objetivam solucionar problemas da vida cotidiana, do exercício da cidadania e do trabalho.

Dessa forma, o presente projeto realizado na Universidade do Estado de Mato Grosso (UNEMAT), campus de Barra de Bugres teve como principal objetivo aproximar os conhecimentos teóricos de uma área relevante para a Engenharia de Alimentos (química e física) às práticas e experimentações através de oficinas e minicursos, expondo dessa forma, o trabalho realizado na Universidade e propiciando o desenvolvimento de competências e habilidades necessárias aos estudantes de ensino médio da região contemplados pelos projetos de extensão da UNEMAT. 


\section{METODOLOGIA}

No presente estudo foram desenvolvidos projetos de extensão vinculados a editais da Universidade do Estado de Mato Grosso (UNEMAT), que ofertaram oficinas sobre conhecimentos teóricos e práticos nas disciplinas de química e física de escolas públicas e particulares, utilizando conceitos técnicos e materiais comumente utilizados no curso de Engenharia de Alimentos da UNEMAT. As oficinas foram ofertadas para estudantes do ensino médio da cidade de Barra do Bugres/MT e outras cidades da região de abrangência da UNEMAT, em diferentes turnos, totalizando 20 horas de atividades. Conforme classificação de Prodanov et al. (2013) esta pesquisa apresenta abordagem qualitativa, e quanto aos procedimentos técnicos é uma pesquisa exploratória.

A seleção de Escolas e turmas atendidas foi feita mediante a inscrição das Escolas de Educação Básica que manifestaram interesse em participar do Projeto. O Projeto foi divulgado através de postagens nas redes sociais, folders e contato em veículos de comunicação, como rádios em Barra do Bugres/MT.

As oficinas foram ministradas em diferentes Escolas, e também no próprio Laboratório de Química do Curso de Engenharia de Alimentos da Universidade do Estado de Mato Grosso. As oficinas foram elaboradas por acadêmicos do curso e pelos professores coordenadores do projeto de extensão, que perceberam a necessidade de integrar conteúdos e conhecimentos teóricos às práticas de sala de aula, além de criar vínculos estreitos entre o contexto escolar e universitário na região.

Nas oficinas, buscou-se integrar conhecimentos requeridos a fim de desenvolver as competências e habilidades necessárias aos estudantes de ensino médio da rede regular, nas disciplinas de química e física. Ao final do projeto, foi ofertado um dia especial de mini oficinas, com várias experiências úteis ao dia a dia, das quais as pessoas podiam se inscrever no ato. O período de desenvolvimento do projeto foi de 2017 a 2019 e foi dividido em três etapas principais, conforme mostrado na Figura 1.

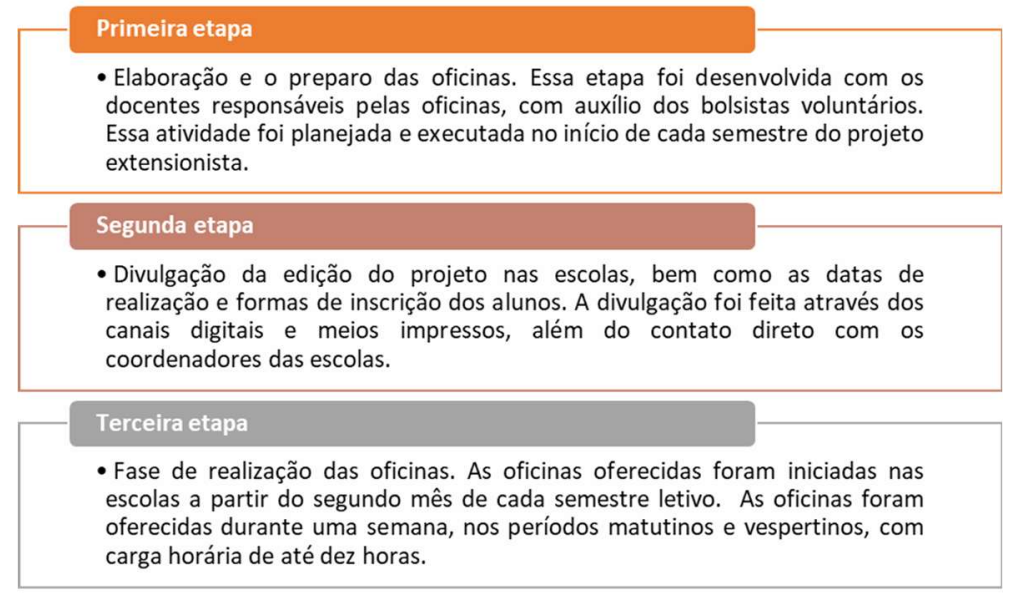

Figura 1: Etapas de realização do projeto.

\section{DISCUSSÃO TEÓRICA}

Neves (2002) aponta que o desempenho dos estudantes não é determinado apenas por suas capacidades cognitivas, mas também pela interação entre os fatores cognitivos e afetivos estabelecidos. Isso foi observado claramente desde a primeira etapa da oficina, onde os alunos participaram, demonstraram 
amplo interesse pelos experimentos abordados, possibilitando maior fixação dos conteúdos teóricos estudados. Tanto pelos estudantes da rede regular, como os universitários integrantes do projeto.

Em consonância com Dourado (2018) percebemos que a trajetória política e econômica adotada no Brasil fez com que o ingresso na universidade seja considerado como uma mercadoria, um produto ou até mesmo um privilégio, ao invés de entendido como um direito. Em face disso, o projeto extensionista que buscou contato direto com a comunidade escolar, também foi responsável pela democratização e facilitação de contato com a universidade, descontruindo o paradigma de universidade distante, já que as oficinas realizadas se adaptaram bem ao contexto dos estudantes participantes.

A interdisciplinaridade entre os grupos universitários e o diálogo intercultural com os membros da comunidade externa criam durante a realização do projeto, um espaço de interlocução, "onde se produzem efeitos de compreensão, tradução e facilitação no plano na comunicação. De acordo com a visão crítica, todos os participantes aprendem em contato com os outros, aceitando relativizar seus pontos de vista" (THIOLLENT, 2006).

Uma ação educacional com propósito emancipatório é um desafio às leis de reprodução social, gerando transformações sociais a partir do fato de as camadas desfavorecidas terem acesso à educação, não apenas acesso ao vigente conhecimento elitizado, mas sobretudo condição de construir conhecimentos novos, em termos de conteúdos, formas e usos. Um mesmo conhecimento tem usos diferenciados que depende dos referenciais de classe, dos campos de atuação e dos meios sociais envolvidos. (THIOLLENT, 2006)

O reconhecimento das oficinas realizadas nas escolas ficou evidente na compreensão dos elementos teóricos aliados à experimentação e prática. Transcrevemos a seguir um relato voluntário de um dos estudantes participantes da oficina em uma turma de segundo ano do Ensino Médio:

"Achei interessante a forma como foram apresentados os conteúdos que temos que estudar nas matérias de química e física. Ficou muito mais fácil de entender esses conteúdos, além disso, foi uma atividade muito diferente e pudemos conhecer um pouquinho de como é o curso de Engenharia de Alimentos" (L.B. - Participante de oficina).

Percebemos a participação e o envolvimento dos alunos como um dos elementos centrais da aprendizagem significativa. O teórico que desenvolveu o conceito de aprendizagem significativa prevê a necessidade do aprendiz se colocar como um sujeito ativo e não meramente passivo no processo de aprendizagem. Cada indivíduo, em sua consciência, possui conhecimentos específicos sobre diversos aspectos. Na infância, é denominado como a formação de conceitos, e isso se dá pela experiência própria de cada um. A aprendizagem significativa se dá na formação de experiências ativas pelos estudantes na construção de conhecimentos. A seguir, Nas Figuras 2, 3, e 4, elucidamos os resultados da implementação do projeto, através da entrega de alimentos produzidos na oficina a um lar beneficente, pelos próprios estudantes participantes das oficinas.

Nesse fluxo, a aprendizagem significativa ocorre quando o aprendiz é capaz de receber novas informações e racionalizar, de forma que possa interagir com o que já se sabe previamente e o que se acabou de conhecer, de maneira Dialógica, conforme os estudos de Bakhtin (2007). 


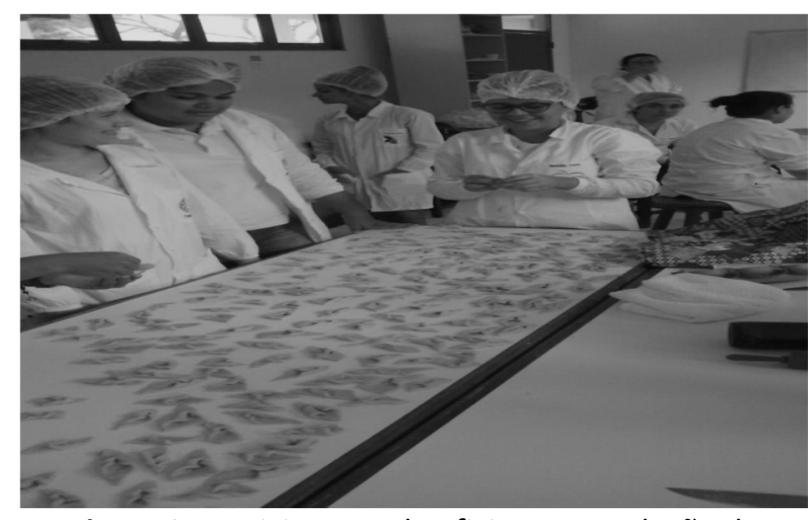

Figura 2: Participantes da oficina na produção de biscoitos.

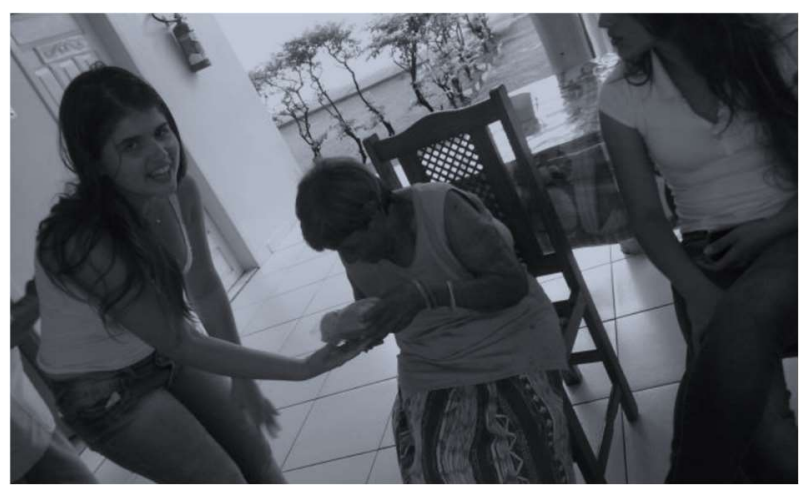

Figura 3: Entrega dos alimentos da oficina de panificação por voluntários.

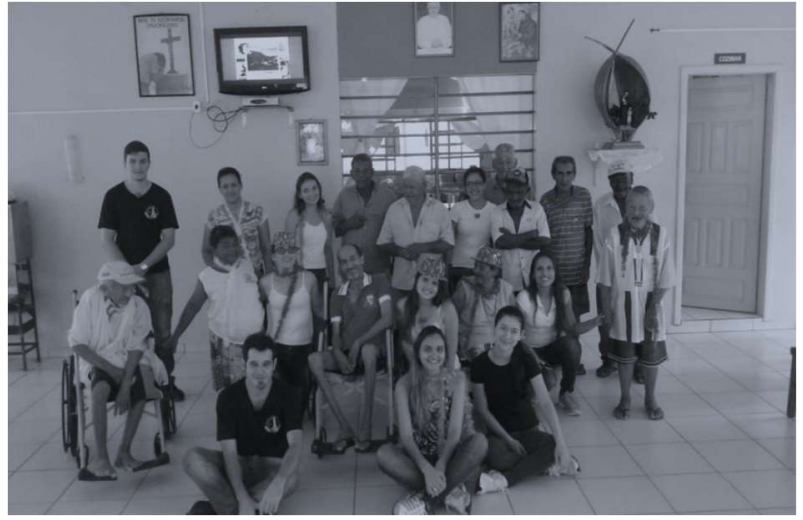

Figura 4: Idosos do Lar São Vicente de Paulo em Barra do Bugres-MT, acompanhados dos estudantes participantes de uma oficina.

Valores como a solidariedade e caridade também são impulsionadores no processo de aprendizagem, como Freire (1991) já discutira em seus estudos. A identificação e pertencimento ao meio social mais amplo são motivadores para a efetivação dos programas de extensão. Em trabalhos similares promovendo a extensão no ensino superior, Rigueto et al. (2017) relataram uma experiência de oficina de fabricação de ovos de chocolate que foram distribuídos para famílias carentes, na qual os participantes extensionistas da oficina se sentiram integrados ao saber social e utilizaram os conhecimentos de maneira significativa e valorativa em suas vidas. No mesmo movimento, Rigueto et al. (2016) realizaram uma reflexão a respeito das possibilidades de ensino de química na rede regular de ensino, através dos saberes úteis ao curso de Engenharia de Alimentos, que auxiliaram no processo de aprendizado dos estudantes, de modo que as experiências traziam elementos utilizados no cotidiano dos alunos e facilitavam a apreensão dos conteúdos teóricos aliados à prática e experimentação proporcionados pelo projeto de extensão.

No método de Ausubel (1982), o conhecimento prévio do indivíduo é chamado de conceito subsunçor, os conceitos e proposições estáveis no indivíduo. Isso garante ao aprendiz a possibilidade de conhecer ideias novas, colaborando com conhecimentos prévios na apreensão de novas informações.

A aprendizagem significativa tem como pressuposto que o novo material conceitual seja relevante e significativo ao aprendiz e à estrutura cognitiva preexistente. Portanto, em consonância com o conceito de assimilação apresentado pelos autores, verifica-se que o aprendiz une o conhecimento prévio aos novos e cria um novo elo em forma de subsunçor. Cada indivíduo constrói uma base de conhecimento. 


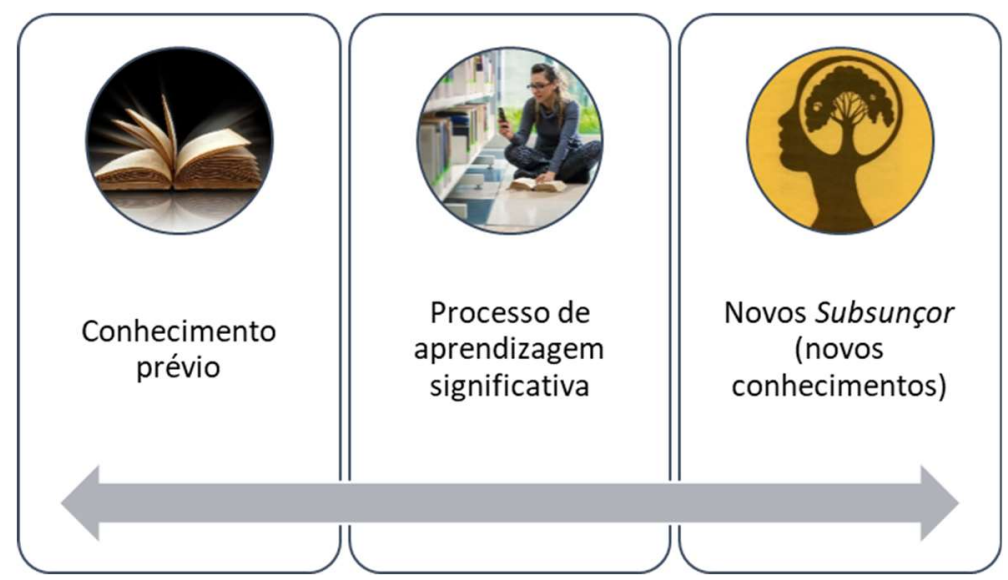

Figura 5: Processo de aprendizagem significativa. Fonte: Adaptado de Ausubel (1982).

Os conceitos são formados e depois assimilados em uma nova imbricação de ideias. É perceptível a mobilização desses conhecimentos na prática que a extensão proporciona aos estudantes. Transcrevemos a seguir o relato de um estudante de terceiro ano do ensino médio que corrobora com os conceitos apresentados:

"Fiquei impressionado como física e química não são tão diferentes quanto parecem. Tinha dificuldade em entender a diferença entre ácidos e bases na disciplina de química, e o pessoal da Universidade ensinou isso de maneira muito prática para a gente, deu para entender como isso tudo funciona. Gostei muito dessa oportunidade" (G.D.L - Participante de oficina).

É importante que sejam criados métodos de organização na ampliação dos projetos de extensão como uma forma de ensino inovadora que visa auxiliar o estudante a explorar por si de maneira autônoma o conhecimento e consiga se tornar um pesquisador com capacidade de assimilar diferentes conhecimentos requeridos ainda na Base Nacional Comum Curricular (2020).

\section{CONCLUSÕES}

São muitas as demandas de ensino, seja na esfera acadêmica ou da educação regular, e as perspectivas de atualização, experimentação e aprendizagem ativa, com o desenvolvimento de atividades atrativas é requisito para o ensino de qualidade. Não se pode mais perceber a universidade como um espaço de saberes isolados, e fragmentado, mas como um espaço de socialização dos saberes e fortalecimento da extensão nesses processos de integração de saberes.

Na realização das oficinas integrantes do projeto de extensão, foi possível despertar o senso de cooperação e interesse nas disciplinas de física e química, através de atividades práticas que resultaram no bem comum, e fortaleceram o senso de solidariedade e o gosto pelo estudo. $O$ vínculo com a comunidade local é fundamental para criar soluções para as problemáticas que envolvem a prática docente. Notamos que o objetivo foi alcançado, uma vez que as oficinas integrantes do projeto, anteriormente discutidas, compreenderam os elementos necessários à aprendizagem significativa.

Quanto às limitações deste estudo, elucidamos que o curto período para realização do projeto, e, consequentemente, o breve período de duração das oficinas limitam o trabalho com a extensão universitária. O espaço dedicado a um artigo científico também limita as possibilidades de discussão sobre as possibilidades 
da extensão, que são inúmeras. Sugerimos a ampliação da temática, através de outros estudos que possam integrar mais experiências significativas e necessárias para a imbricação entre as universidades e a sociedade.

É fundamental que as Instituições de Ensino Superior se capacitem e integrem os projetos de extensão de modo mais abrangente em suas vivências docentes, a fim de aproximar e ampliar os elos com a comunidade, qualificando os processos de aprendizagem e potencializando ações participativas e transformando a universidade em um espaço de aprendizagem plural e participativa.

\section{REFERÊNCIAS}

AUSUBEL, D. P.. A aprendizagem significativa: a teoria de David Ausubel. São Paulo: Moraes, 1982.

BAKHTIN, M.. Marxismo e filosofia da linguagem. 7 ed. São Paulo: Hucitec, 1995.

BRASIL. Ministério da Educação. Base Nacional Curricular Comum. Brasília: MEC, 2017.

DOURADO, I. P.. Educação Superior e a identidade Comunitária-Desafios da extensão, inclusão e permanência. Expressa Extensão, v.23, n.3, p.107-124, 2018

FREIRE, P.. A educação na cidade. São Paulo: Cortez, 1991.

PRODANOV, C. C.; FREITAS, E. C.. Metodologia do trabalho científico: métodos e técnicas da pesquisa e do trabalho acadêmico. Novo Hamburgo: Feevale, 2013.
RIGUETO, C. V. T.; GUEDES, S. F.; KOCHHANN, M. E. R.; LEAL, I. F. M.; CARVALHO, J. W. P.. Possibilidades do ensino de química envolvendo a industrialização de alimentos. Educationis, v.4, n.1, p.15-20, 2016.

RIGUETO, C. V. T.; GUEDES, S. F.; LOSS, R. A.; SOUSA, S.; FERRÃO, G. S.. Oficina de chocolate: ensinando o sabor da solidariedade e cidadania. Educationis, v.5, n.1, p.14-20, 2017.

SAUER, C. R. T.. Extensão universitária: mobilizadora de processos democráticos na gestão da educação. Passo Fundo: UPF, 2018.

THIOLLENT, M.. A inserção da pesquisa-ação no contexto da extensão universitária. Pesquisa participante: a partilha do saber. Aparecida: Ideias e Letras, n.45, p.151-65, 2006.

VYGOTSKY, L. S.. A formação social da mente. São Paulo: Martins Fontes, 2002.

A CBPC - Companhia Brasileira de Produção Científica (CNPJ: 11.221.422/0001-03) detém os direitos materiais desta publicação. Os direitos referem-se à publicação do trabalho em qualquer parte do mundo, incluindo os direitos às renovações, expansões e disseminações da contribuição, bem como outros direitos subsidiários. Todos os trabalhos publicados eletronicamente poderão posteriormente ser publicados em coletâneas impressas sob coordenação da Sapientiae Publishing, da Companhia Brasileira de Produção Científica e seus parceiros autorizados. Os (as) autores (as) preservam os direitos autorais, mas não têm permissão para a publicação da contribuição em outro meio, impresso ou digital, em português ou em tradução. 